Original Article

\title{
Endoscopic Discectomy versus Microscopic Discectomy
}

\author{
ljaz Hussain Wadd, Sidra ljaz, Naem-ul-Hasan \\ Department of Neurosurgery, Punjab Institute of Neurosciences (PINS), Lahore, Pakistan
}

\begin{abstract}
Objective: A randomized control trial was conducted to compare the outcome of an endoscopic discectomy with microdiscectomy in lumbar spine disc disease.
\end{abstract}

Material and Methods: A randomized control trial was conducted at the Department of Neurosurgery, Punjab Institute of Neurosciences (PINS), Lahore. We included 80 patients of ages between $13-65$ years, with low backache with radiation towards legs and prolapsed intervertebral disc at L5 - S1 and L4 - L5 levels on MRI were included in the study. Endoscopic/microscopic discectomy was done in a randomized manner under general anesthesia in a prone position with fluoro guidance. Postoperatively, all patients stayed in the recovery room for two hours for monitoring and then shifted to the ward. All patients followed-up-to one year clinically with the help of the Oswestry disability index (ODI).

Results: There were 37 female and 43 male patients in the ages between $13-65$ years. The mean age of patients was 53.5 years. The 53 patients were having prolapsed disc at L5 S1 levels and 27 patients with disc prolapse at L4 - 5 levels. A good improvement was observed in visual analog scores after surgery in both endoscopic and microscopic discectomy groups. But endoscopic discectomy group required a lesser hospital stay, early mobilization, and lesser postoperative analgesia requirements than the microscopic group.

Conclusion: Endoscopic/microdiscectomy both are equally effective and safer techniques. They both can relief. However, the endoscopic discectomy was found better in terms of early mobilization and lesser postoperative pain.

Keywords: Endoscopic Discectomy, Lumbar Disc Prolapse, Backache, Oswestry Disability Index (ODI), Visual Analog Score (VAS).

Corresponding Author: ljaz Hussain Wadd

Department of Neurosurgery

Punjab Institute of Neurosciences (PINS), Lahore

Email: drejazns@gmail.com

Date of Submission: 20-02-2021

Date of Revision: 22-03-2021

Date of Online Publishing: 31-03-2021

Date of Print: 31-03-2021

DOI: $10.36552 /$ pjns.v25i1.532

\section{INTRODUCTION}

The most common presentation of the prolapsed intervertebral disc is backache with radiation towards legs that can be severe enough with no response to the medicine and surgical intervention may be needed. The Intervertebral disc is composed of a nucleus pulposus surrounded by an annulus fibrosus. The disc prolapse starts with wear and tear in the annulus fibrosus followed by herniation of the nucleus 
pulposus. The back pain radiating towards the legs is called sciatica and sciatica is so common that it affects millions of peoples in the world. ${ }^{1}$ The prolapsed disc causes compression over the nerve roots with inflammation of roots and release of inflammatory mediators causing pain. ${ }^{2}$ More severe compression can lead to multiple nerve palsies and cauda equina syndrome can develop in such patients. ${ }^{3}$ The discogenic low back pain is due to morphological changes inside the disc material that leads to pain. ${ }^{4}$ When this pain correlates with morphological changes inside the disc then it may need discectomy. There are many surgical options available for this; open, microscopic, or endoscopic approach. Open surgery has more morbidity due to muscle damage and soft tissue trauma. These muscles play an important role in segmental stability. ${ }^{5}$ Many neurosurgeons and spine surgeons believe that minimally invasive surgery gives better results. With a better understanding of the anatomy of the spinal column the 'Kambin triangle' is the safe area to operate over the lumbar disc. ${ }^{6}$ With better understanding now transforaminal discectomy is being done through this triangle approach. In $10-20 \%$ of patients with sciatic symptoms, conservative treatment does not work and patients require surgery. ${ }^{7}$

Many neurosurgeons believe that open laminectomy gives a good exposure and better orientation of anatomy and most commonly performed and accepted with minimum chances of injury to nerve roots, damage to facet joints, and minimum chances of instability. ${ }^{8}$ Recently, endoscopic discectomy is also commonly performed because its minimally invasive with less trauma to muscles and had fast recovery. ${ }^{8}$ Due to advancements in endoscopic tools and a better understanding of technique, the indications are increasing now for it. ${ }^{9}$

\section{MATERIAL AND METHODS}

\section{Study Design \& Settings}

Randomized Central Trial (RCT). This study was carried out at the Department of Neurosurgery, Unit II, Punjab Institute of Neurosciences (PINS), Lahore. All the 80 patients presented in the outpatient department were admitted to the ward and operated microscopically and endoscopically under GA (general anesthesia) in the prone position in a randomized manner. Peroperative $C$ arm help was also taken in both endoscopic and microscopic groups. The informed consent was taken from all patients included in the study. The approval was taken from the ethical committee of the hospital.

\section{Inclusion Criteria}

All the patients with sciatic symptoms between 13 - 65 years of age and both sexes were included in the study.

\section{Exclusion Criteria}

Patients more than 65 years of age, medically unfit patients, upper lumbar disc, multilevel disc disease, and central disc were excluded from the study.

\section{Data Collection}

All patients with low backache with radiation towards legs with positive SLR (straight leg raising test) and with or without clinical signs were thoroughly investigated. Data was entered on the predesigned performa.

\section{Clinical Management}

All basic blood tests along with X-ray chest and ECG were done if age more than 45 years. MRI lumbosacral spine was obtained and properly evaluated. X-ray lumbosacral spine was also conducted. The patients more than 65 years of age, medically unfit, upper-level disc or multilevel 
disc degeneration on MRI, lumbar disc associated with spinal stenosis were excluded from the study. After surgery, all patients were shifted to neuro ICU for 2hours and then shifted to the neuro ward for proper post-op care. Standard nursing care and rehabilitation care were given to all patients. All patients were discharged on the first operative day. A visual analog score (VAS) scale and Oswestry Disability Index (ODI) scales were used for the comparison of pre and postoperative in discectomies (microscopic and endoscopic).

\section{Follow-up}

All patients were followed clinically and radiologically in OPD. All patients were followed at $10^{\text {th }}$ post-op day, 1 month, 3 months, 6 months, and at 1 year.

\section{Data Analysis}

All the data was entered and analyzed by SPSS version 22.0. All the descriptive and quantitative data was entered and analyzed by SPSS version 22.0. Chi-square test was employed to calculate the statistical significance in the comparison. A pvalue $<0.05$ was taken the significant.

\section{RESULTS}

\section{Gender Distributions}

We studied the 80patients in our department operated from Jan 2016 to Jan 2019, which included 37 female and 43 male.

\section{Age Range}

Patients with ages range between $13-65$ years. All patients presented to us with low back pain and sciatic symptoms. The mean age of patients was 53.5 years.

\section{Clinical Presentation}

The 53 patients were having prolapsed disc at L5 S1 levels and 27 patients with disc prolapse at L45 levels. We did endoscopic/microscopic discectomy in a randomized manner. We compared in our study the outcome of endoscopic versus microscopic discectomies in patients. We followed the patients at 3 weeks, 3 months, 6 months and one year.

\section{Comparison}

A much improvement was observed in VAS as well as in ODI scores after surgery in both endoscopic and microscopic discectomies. The endoscopic discectomy group required a lesser hospital stay and early mobilization and lesser analgesic requirements (Tables 1,2 ). Table 3 compares the results of both groups and showed that both techniques give excellent and good results.

\begin{tabular}{|lcc|}
\hline Table 1: VAS (Visual Analog Score). \\
Technique & $\begin{array}{c}\text { Mean Preoperative } \\
\text { VAS }\end{array}$ & $\begin{array}{c}\text { Mean } \\
\text { Postoperative VAS }\end{array}$ \\
Endoscopic & 7.3 & 2.3 \\
Discectomy & & 4.45 \\
Microscopic & 7.1 & \\
Discectomy & & \\
\hline
\end{tabular}

Table 2: Mean Oswestry Disability Index (ODI).

\begin{tabular}{lcc} 
Technique & $\begin{array}{c}\text { Mean ODI } \\
\text { Preoperative }\end{array}$ & $\begin{array}{c}\text { Mean ODI } \\
\text { Postoperative }\end{array}$ \\
$\begin{array}{l}\text { Endoscopic } \\
\text { Discectomy }\end{array}$ & 65.1 & 22.50 \\
$\begin{array}{l}\text { Microscopic } \\
\text { Discectomy }\end{array}$ & 66.3 & 24.30 \\
\hline
\end{tabular}


Table 3: Microscopic and Endoscopic ODI score.

ODI Score

Excellent $(0-20)$

Good $(21-40)$

Fair $(41-60)$

Poor $(>60)$

\begin{tabular}{ll} 
Microscopic & Endoscopic \\
$35 \%(28)$ & $30 \%(24)$ \\
$65 \%(52)$ & $70 \%(56)$ \\
0 & 0 \\
0 & 0 \\
\hline
\end{tabular}

\section{Chi Square $\left(\chi^{2}\right)$ and $p$ value}

$0.445 ; p$ value: 0.499

\section{DISCUSSION}

We are performing endoscopic discectomies in our unit for lumbar disc disease because it's minimally invasive with less complication and had a good outcome. The study also concludes that endoscopic spine surgeries are minimally invasive with fewer complications and favorable outcome. ${ }^{13}$ We also noticed in our endoscopic surgery groups the minimal postoperative surgery site pain postoperatively because of minimum trauma to the muscle, soft tissue, and bones and minimum manipulation of nerve roots when compared with microscopic discectomy. The incision size of endoscopic discectomy was small as compared to microscopic discectomy in our study and microscopic discectomy also requires more retraction of muscles and bony work. In another study, in microdiscectomy, they gave a large size incision with the use of a retractor and more bony work done along with partial removal of the ligamentum flavum. ${ }^{12}$ In our study, we noticed good postoperative radicular pain relief in endoscopic and microscopic discectomy patients with no recurrence of symptoms. But contrary to our research, some studies have seen a recurrence of postoperative pain in endoscopic discectomies. They claim that recurrence of pain may be due to extensive epidural fibrosis causing compression over nerve roots. ${ }^{13,14}$ Many reported complications of endoscopic discectomies require conversion to open surgery; durotomy with pseudomeningocele formation, meningitis, and discitis. ${ }^{15,16}$ No such complications occur in our study and no case of endoscopic discectomy was converted to open surgery. In three of our patient wound infections occurs that was treated with dressing change and intravenous antibiotics according to culture report. We followed all our patients for up to one year for any recurrence of symptoms and no recurrence of symptoms were noted during this time period. $\mathrm{Xu}$, et $\mathrm{al}^{17}$ also reported in their study no such complications nor any recurrence. But in another study, they reported the nerve root injury by $\mathrm{Hsu}$, et $\mathrm{al}^{18}$ Sencer, et $\mathrm{al}^{19}{ }^{19}$ in their study noted $5.8 \%$ chances of iatrogenic durotomy but we did not report any case of durotomy in any of our patients. Many studies also reported their recurrence rate of 3 $4 \%{ }^{19}$

\section{Limitations}

The limitation of my study is that it is a singlecenter study with a small sample size and followup is also not so long. A larger multicentric study with a large number of patients is required to finalize the opinion and recommendations.

\section{CONCLUSION}

Endoscopic and microscopic discectomies are equally safe and effective techniques for removal of the lumbar disc on longer follow-up. However, the Endoscopic discectomy was found better than the microscopic discectomy in the short term outcome because of early mobilization and lesser postoperative pain. The endoscopic technique is safe in many hands who have sound knowledge of spinal anatomy. 


\section{REFERENCES}

1. Konstantinou K, Dunn KM. Sciatica: review of epidemiological studies and prevalence estimates. Spine, 2008; 33: 2464-2472.

2. Boonstra AM, Preuper HRS, Reneman MF, Posthumus JB, Stewart RE. Reliability and validity of the visual analogue scale for disability in patients with chronic musculoskeletal pain. Int J Rehabil Res. 2008; 31: 165-169.

3. Ma D, Liang Y, Wang $D$, Liu Z, Zhang W, Ma T, et al. Trend of the incidence of lumbar disc herniation: decreasing with aging in the elderly. Clin Interv Aging, 2013; 8: 1047-1050.

4. Mixter WJ, Barr JS. Rupture of intervertebral disc with involvement of spinal canal. New Eng. J Med. 1934; 211: 210-14.

5. Ward SR, Kim CW, Eng CM et al. Architectural analysis and intraoperative measurements demonstrate the unique design of the multifidus muscle for lumbar spine stability. J Bone Jt Surg Am. 2009; 91 (1): 176-185.

6. Kambin P. Arthroscopic Microdiscectomy Minimal Intervention. In: Kambin P (Ed). Spinal Surgery. Text Urban and Schwarzenberg Baltimore, MD, 1991: pp. 67-100.

7. Gautschi OP, Cadosch D, Hildebrandt G.Acute low back pain-assessment and management. Praxis. 2008; 97 (2): 58-68.

8. Wenger M, Mariani L, Kalbarczyk A, Gröger U. Long-term outcome of 104 patients after lumbar sequestrectomy according to Williams. Neurosurgery, 2001; 49 (2): 329-335.

9. J. N. A. Gibson, J. G. Cowie, and M. Iprenburg. Transforaminal endoscopic spinal surgery: the future 'gold standard' for discectomy?-a review. The Surgeon, 2012; 10 (5): 290-296.

10. Ruetten S, Komp M, Merk H, Godolias G, Recurrent lumbar disc herniation after conventional discectomy: a prospective, randomized study comparing full-endoscopic interlaminar and transforaminal versus microsurgical revision. Journal of Spinal Disorders \& Techniques, 2009; 22
(2): 122-129.

11. Lewandrowski K-U. Incidence, management, and cost of complications after transforaminal endoscopic decompression surgery for lumbar foraminal and lateral recess stenosis: a value proposition for outpatient ambulatory surgery. Int J Spine Surg. 2019; 13 (1): 53-67.

12. Ruetten S, Komp M, Merk H, Godolias G. Fullendoscopic interlaminar and transforaminal lumbar discectomy versus conventional microsurgical technique: a prospective, randomized, controlled study. Spine (Phila $\mathrm{Pa}$ 1976), 2008; 33 (9): 931-939.

13. Yeung A, Gore S. Endoscopic foraminal decompression for failed back surgery syndrome under local anesthesia. Int J Spine Surg. 2014; 8: 22.

14. Ross JS, Robertson JT, Frederickson RCA, et al. Association between peridural scar and recurrent radicular pain after lumbar discectomy: magnetic resonance evaluation. Neurosurgery, 1996; 38 (4): 855-861.

15. Teli M, Lovi A, Brayda-Bruno M, Zagra A, Corriero $A$, Giudici $F$, et al. Higher risk of dural tears and recurrent herniation with lumbar microendoscopic discectomy. Eur Spine J. 2010; 19: 44350.

16. Zhou $Y$, Wang $M$, Wang J, Chu TW, Zhang ZF, Li $C Q$. Clinical experience and results of lumbar microendoscopic discectomy: A study with a fiveyear follow-up. Orthop Surg. 2009; 1: 171-5.

17. Xu H, Liu X, Liu G, Zhao J, Fu Q, Xu B. Learning curve of full-endoscopic technique through interlaminar approach for L5/ S1 disk herniations. Cell Biochem Biophys. 2014; 70: 1069-74.

18. Hsu HT, Chang SJ, Yang SS, Chai CL. Learning curve of full-endoscopic lumbar discectomy. Eur Spine J. 2013; 22: 727-33.

19. Fei $Q$, Li J, Lin J, et al. Risk factors for surgical site infection after spinal surgery: a metaanalysis. World Neurosurg. 2016; 95: 507-515. 


\section{Additional Information}

Disclosures: Authors report no conflict of interest.

Ethical Review Board Approval: The study was conformed to the ethical review board requirements.

Human Subjects: Consent was obtained by all patients/participants in this study.

Conflicts of Interest:

In compliance with the ICMJE uniform disclosure form, all authors declare the following:

Financial Relationships: All authors have declared that they have no financial relationships at present or within the previous three years with any organizations that might have an interest in the submitted work.

Other Relationships: All authors have declared that there are no other relationships or activities that could appear to have influenced the submitted work.

\section{AUTHORS CONTRIBUTIONS}

\begin{tabular}{|l|l|l|}
\hline Sr.\# & Author's Full Name & Intellectual Contribution to Paper in Terms of: \\
\hline 1. & ljaz Hussain Wadd & Analysis of data, study design and methodology. \\
\hline 2. & Sidra ljaz & Literature review \& Statistical analysis. \\
\hline 3. & Naem-ul-Hasan & Data Collection. \\
\hline
\end{tabular}

